\title{
THE RELATIVE SENSITIVITY OF FORMABILITY TO ANISOTROPY
}

\author{
Roger W. Logan \\ Lawrence Livermore National Laboratory \\ Livermore, CA \\ Bradley N. Maker \\ Livermore Software Technology Corp. \\ Livermore, CA
}

This paper was prepared for submittal to

1997 Society of Automotive Engineers, International Congress and Exhibition

Detroit, MI

February 24-27, 1997

\section{January 1997}

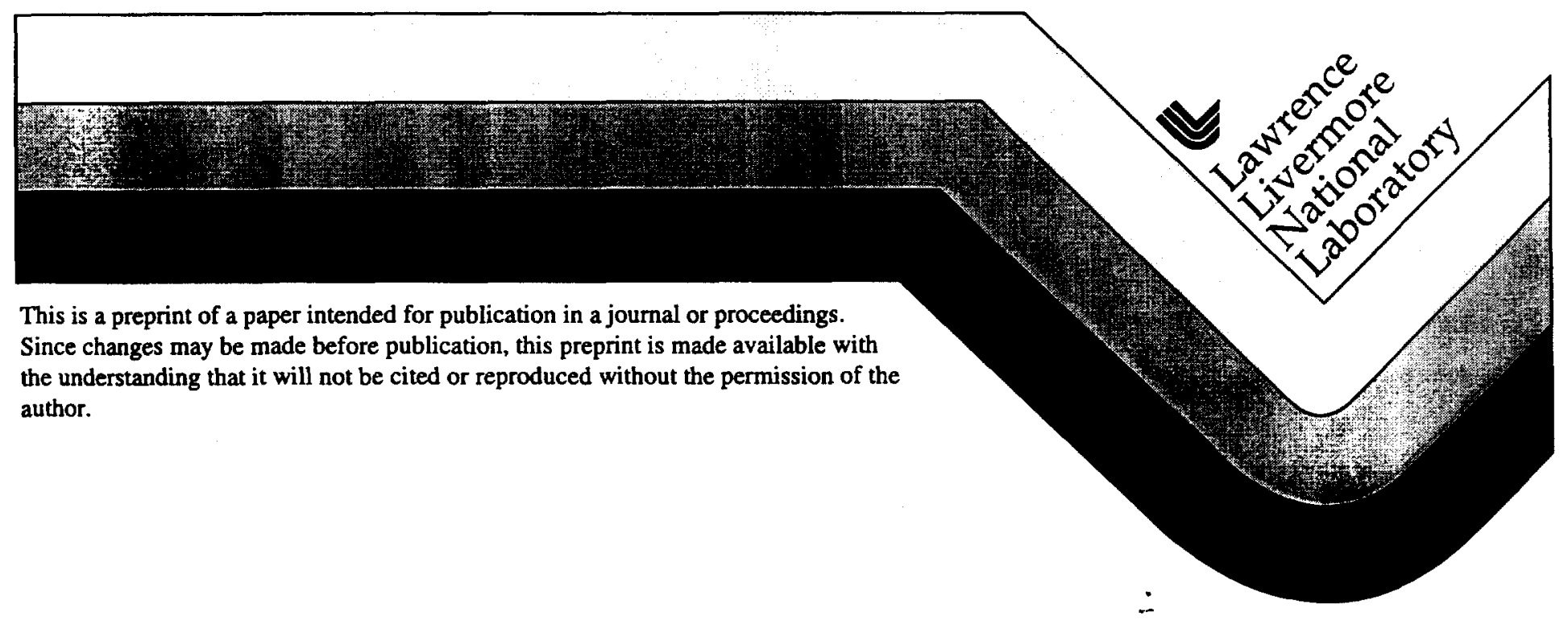


DISCLAIMER

This document was prepared as an account of work sponsored by an agency of the United States Government. Neither the United States Government nor the University of California nor any of their employees, makes any warranty, express or implied, or assumes any legal liability or responsibility for the accuracy, completeness, or usefulness of any information, apparatus, product, or process disclosed, or represents that its use would not infringe privately owned rights. Reference herein to any specific commercial product, process, or service by trade name, trademark, manufacturer, or otherwise, does not necessarily constitute or imply its endorsement, recommendation, or favoring by the United States Government or the University of California. The views and opinions of authors expressed herein do not necessarily state or reflect those of the United States Government or the University of California, and shall not be used for advertising or product endorsement purposes. 


\title{
THE RELATIVE SENSITIVITY OF FORMABILITY TO ANISOTROPY
}

\author{
Roger W. Logan \\ Lawrence Livermore National Laboratory \\ (LLNL) \\ Livermore, CA \\ Bradley N. Maker \\ Livermore Soltware Technology Corp. \\ (LSTC) \\ Livermore, CA
}

\begin{abstract}
This work compares the relative importance of material anisotropy in sheet forming as compared to other material and process variables. The comparison is made quantitative by the use of normalized dependencies of depth to failure (forming limit is reached) on various measures of anisotropy, as well as strain and rate sensitivity, friction, and tooling. Comparisons are made for a variety of forming processes examined previously in the literature as well as two examples of complex stampings in this work. The examples cover a range from nearly pure draw to nearly pure stretch situations, and show that for materials following a quadratic yield criterion, anisotropy is among the most sensitive parameters influencing formability. For materials following higher-exponent yield criteria, the dependency is milder but is still of the order of most other process parameters. However, depending on the particular forming operation, it is shown that in some cases anisotropy may be ignored, whereas in others its consideration is crucial to a good quality analysis.
\end{abstract}

\section{INTRODUCTION AND MOTIVATION}

This work was motivated in part by the findings of one of the authors in a previous work [1], but in large part flavored by timely discussions at the NUMISHEET 96 and as documented in those proceedings [2]. The large quantity of information assembled in the Limiting Dome Height (LDH) benchmark has allowed the question to be credibly raised as to the relative (quantitative) importance of anisotropy as compared to other sensitivities in sheet forming processes. Since a sensitivity study was performed by many of the entrants in the LDH Simulation Benchmark (SB-1) of NUMISHEET 96, the key aspects of the conclusions of this work had their origins in an examination of that data. However, since SB-1 involved the LDH test, which is predominantly stretch in nature, it was felt that any attempt to be even moderately thorough in examining relative sensitivities should include a variety of forming operations. To that end, quantitative statements are developed below regarding what is important during the following forming operations:

draw situation:

LDR (Limiting Draw Ratio) [3], predominantly a LDH (Limiting Dome Height) [2], a predominantly stretch operation:

Conical Cupping [4-6], where inhibition of wrinkling demands a stretch/draw balance:

Earing during Cupping $[7,8]$, another process where draw is the main mode:

Blank shape optimization for a rectangular box $[1,9]$, a stretch/draw situation:

Blank shape for a cylindrical cup [1], a draw dominated situation:

Hydroforming of a "fish"-shaped cover plate [10], a stretchidraw operation:

Closed-die stamping of an aircraft door frame [11], predominantly stretch with some draw component.

The pertinent information about these processes is reviewed below and summarized in a form that reveals where each material and process parameter is most relevant. Included in these is the means of characterizing the anisotropy; this may be viewed in a hypothetical way regarding which of several yield surfaces is chosen numerically to represent the material, or alternately in terms of the realism to which each criterion captures a given sheet material's measured properties. The various criterion chosen as extensions to the isotropic Von Mises include the 1948 Hill [12], also called H48 or " $a=2$ " in this work, the 1979 New Hiil, form \#4 [13], also referred to as NH4 or "a<2" in this work, and the 1979 Hosford [14], also called $\mathrm{H79}$ or " $\mathrm{a}=8$ " in this work. Since that criterion is numerically similar to the one proposed by Barlat and Lian in 1989 [15], the latter will be included in the " $a=8$ " nomenclature in this work. Forms of these criterion have been implemented into versions of W-DYNA3D at LLNL [1], and into LSDYNA3D and LS-NIKE3D at LSTC $[16,17]$. form:

\footnotetext{
The quadratic 1948 Hill yield surface takes the
} 
$\bar{\sigma}^{2}=\frac{F\left(\sigma_{b}-\sigma_{c}\right)^{2}+G\left(\sigma_{c}-\sigma_{a}\right)^{2}+H\left(\sigma_{a}-\sigma_{b}\right)^{2}+D}{R+1}$

Eqn. (1) relates the effective stress to the three normal components of Cauchy stress, with the term $D$ containing the shear stress terms:

$$
D=2 L \sigma_{b c}^{2}+2 M \sigma_{c a}^{2}+2 N \sigma_{\infty}^{2}
$$

- The values for the constants in Eqns. (1) and (2) can be expressed in terms of the in-plane strain ratios $R=R_{0}, Q=R_{45}$, and $P=R_{90}$, and $S=R / P$, with the following additional relations needed:

$$
\begin{aligned}
& F=S=(R / P) \\
& G=1 \\
& H=R \\
& L=\left(Q_{b c}+\frac{1}{2}\right)(R+1) \\
& M=\left(Q_{c a}+\frac{1}{2}\right)(R+S) \\
& N=\left(Q_{a b}+\frac{1}{2}\right)(1+S)
\end{aligned}
$$

This "a=2" criterion is comparatively straightforward to implement, but is unable to account for the so-called 'anomalous' behavior observed in certain metals (some aluminum alloys and others) where $R<1$ but biaxial strength is still greater than uniaxial. In an attempt to capture this behavior, the "\#4" variant of Hill's 1979 general form may be used [14]:

$$
\bar{\sigma}^{a}=\frac{\left|\sigma_{1}+\sigma_{2}\right|^{a}+(2 \bar{R}+1)\left|\sigma_{1}-\sigma_{2}\right|^{a}}{2(\bar{R}+1)}
$$

In eqn. (4), the intent is an assumption of planar isotropy (i.e. $R=Q=P$ ), and that the exponent $a \leq 2$, hence the nomenclature in this work. Simultaneously, Hosford [14] proposed a higher-exponent yield criterion which has shown better agreement with experiment and crystal plasticity calculations:

$$
\bar{\sigma}^{a}=\frac{F\left(\sigma_{2}-\sigma_{3}\right)^{a}+G\left(\sigma_{3}-\sigma_{1}\right)^{a}+H\left(\sigma_{1}-\sigma_{2}\right)^{a}}{R+1}
$$

This equation is referred to as " $a=8$ " in the current work; it is often used with $a=8$ for foc metals and $a=6$ for $b c c$, with only minor differences due to that subtlety.

In order to circumvent the stress space limitation of the 1979 Hosford criterion, Barlat and Lian [15] introduced a criterion which offers all the advantages of the 1979 Hosford for the case of normal anisotropy $(\Delta R=0)$ but permits the introduction of a coupled shear term while retaining convexity of the yield surface and coordinate system invariance. This criterion is expressed below as in [15], except that we retain the use of ' $a$ as the yield criteria exponent since many of our DYNA implementations refer to ' $m$ ' as a strain-rate exponent. Note also that to avoid confusion we have expressed the coefficient (2-c) explicitly:

$$
\begin{aligned}
& \bar{\sigma}^{a}=\frac{(2-c)\left\{\left|K_{1}+K_{2}\right|^{a}+\mid K_{1}-\right.}{2} \\
& K_{1}=\frac{\dot{\sigma_{a}}+h \sigma_{b}^{\prime}}{2} \\
& K_{2}=\sqrt{\left(\frac{\dot{\sigma_{a}}-h \sigma_{b}^{\prime}}{2}\right)^{2}+p^{2} \sigma_{a b}^{2}} \\
& \sigma_{a}^{\dot{y}}=\sigma_{a}-\sigma_{c} \\
& \dot{\sigma_{b}^{\prime}}=\sigma_{b}-\sigma_{c}
\end{aligned}
$$

The Cauchy stresses must be defined to allow for a third (normal) stress, even though the implementation here is for the shell element in DYNA. This is because the plane-stress material routine is iterative so that even though the normal stress vanishes at convergence, we must recognize its presence during the iterations. Parameters $c, h$, and $p^{*}$ may be defined in the current notation as follows:

$$
\begin{aligned}
& c=2 \sqrt{\left(\frac{R}{1+R}\right)\left(\frac{P}{1+P}\right)} \\
& h=\sqrt{\frac{R(1+P)}{P(1+R)}} \\
& p^{*}=\sqrt{\frac{\left(2 Q_{e b}+1\right)(1+S)}{(1+R)(2+c)}}
\end{aligned}
$$

The value of $p$ is needed for the shear term in eqn (6). In the case of $a=2$, we have $p=p^{*}$. However, this is also the case where the criterion reduces identically to 1948 Hill and is thus of interest only for verification. In general, the value of $p^{*}$ must be found iteratively as described by Barlat and Lian in [15].

The yield criteria just described were used in various contexts with the set of forming problems above in previous works and in the current one. Anisotropy parameters ( $R$-values) for most of the materials herein are as given in Table 1. Other details of the material properties for the sheet materials in Table 1 have been described elsewhere [1-2,10-11].

The sensitivities to the various forming parameters take on a form related to that introduced by one of the authors (RWL) at the NUMISHEET 96 discussion. That is, dependencies on each material or process parameter are normalized to a nominal value of that parameter, and the change in depth to failure $\left(\mathrm{H}^{*}\right.$ in $\mathrm{mm}$ ) is normalized to a nominal value of punch depth for that particular forming operation. Thus, a set of normalized slopes or derivatives, key to following this work, is generated, expressed as percents: 


$$
\begin{aligned}
& R=\left(\frac{\partial H^{*}}{\partial \bar{R}}\right)\left(\frac{\bar{R}}{H^{*}}\right) \\
& \Delta R=\left(\frac{\partial H^{*}}{\partial \Delta R}\right)\left(\frac{\Delta R}{H^{*}}\right) \\
& (R / P)^{\prime}=\left(\frac{\partial H^{*}}{\partial(R / P)}\right)\left(\frac{(R / P)}{H^{*}}\right) \\
& n^{\prime}=\left(\frac{\partial H^{*}}{\partial n}\right)\left(\frac{n}{H^{*}}\right) \\
& m^{\prime}=\left(\frac{\partial H^{*}}{\partial n}\right)\left(\frac{m}{H^{*}}\right) \\
& \mu^{\prime}=\left(\frac{\partial H^{*}}{\partial \mu}\right)\left(\frac{\mu}{H^{*}}\right) \\
& F^{\prime}=\left(\frac{\partial H^{*}}{\partial F}\right)\left(\frac{F}{H^{*}}\right) \\
& B^{\prime}=\left(\frac{\partial H^{*}}{\partial B}\right)\left(\frac{B}{H^{*}}\right) \\
& d^{\prime}=\left(\frac{\partial H^{*}}{\partial d}\right)\left(\frac{d}{H^{*}}\right) \\
& p^{\prime}=\left(\frac{\partial H^{*}}{\partial p}\right)\left(\frac{p}{H^{*}}\right)
\end{aligned}
$$

Table 1. Plastic anisotropy for contrived and real material data sets used in this work.

\begin{tabular}{|l|l|l|l|l|l|l|l|l|}
\hline Matl & $R$ & $Q_{a b}$ & $P$ & $\bar{R}$ & $\frac{\Delta R}{R}$ & $\frac{\Delta P}{R}$ & $\frac{\Delta P}{P}$ & $R$ \\
\hline
\end{tabular}

Materials Used in E45 Earing - Contrived

\begin{tabular}{|l|l|l|l|l|l|l|l|l|}
\hline $\mathrm{Sa}$ & 4.00 & 1.00 & 4.00 & 2.50 & 1.20 & 0.00 & 0.00 & 1.00 \\
\hline $\mathrm{Sb}$ & 2.00 & 1.00 & 2.00 & 1.50 & 0.67 & 0.00 & 0.00 & 1.00 \\
\hline $\mathrm{Sc}$ & 1.50 & 1.00 & 1.50 & 1.25 & 0.40 & 0.00 & 0.00 & 1.00 \\
\hline $\mathrm{Sd}$ & 0.50 & 1.00 & 0.50 & 0.75 & -0.67 & 0.00 & 0.00 & 1.00 \\
\hline $\mathrm{Se}$ & $1.0 \mathrm{~d}$ & 2.00 & 1.00 & 1.50 & -0.67 & 0.00 & 0.00 & 1.00 \\
\hline $\mathrm{Si}$ & 0.50 & 2.00 & 0.50 & 1.25 & -1.20 & 0.00 & 0.00 & 1.00 \\
\hline
\end{tabular}

Materials Used in E90 Earing - Contrived

\begin{tabular}{|l|l|l|l|l|l|l|l|l|}
\hline $\mathrm{Ni}$ & 4.00 & 1.00 & 4.00 & 2.50 & 1.20 & 0.00 & 0.00 & 1.00 \\
\hline
\end{tabular}

\begin{tabular}{|l|l|l|l|l|l|l|l|l|}
\hline $\mathrm{Ni}$ & 1.00 & 2.00 & 3.00 & 2.00 & 0.00 & -1.00 & -1.00 & 0.33 \\
\hline
\end{tabular}

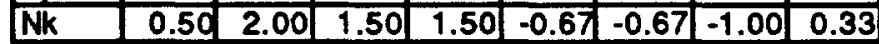

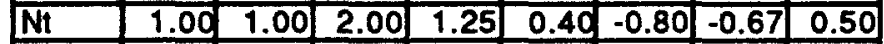

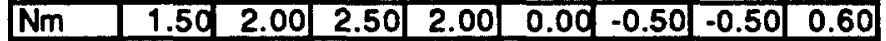

\begin{tabular}{|l|l|l|l|l|l|l|l|l|}
\hline $\mathrm{Nn}$ & 1.00 & 4.00 & 1.00 & 2.50 & -1.20 & 0.00 & 0.00 & 1.00 \\
\hline
\end{tabular}

\begin{tabular}{|l|l|l|l|l|l|l|l|l|}
\hline $\mathrm{Nu}$ & 0.68 & 1.31 & 0.68 & 0.99 & -0.64 & 0.00 & 0.00 & 1.00 \\
\hline
\end{tabular}

Materials Used in E45 \& E90 - W\&B Experimental

\begin{tabular}{|l|l|l|l|l|l|l|l|l|}
\hline$W_{p}$ & 0.77 & 1.31 & 0.58 & 0.99 & -0.64 & 0.19 & 0.28 & 1.33 \\
\hline
\end{tabular}

\begin{tabular}{|l|l|l|l|l|l|l|l|l|}
\hline $\mathrm{Wb}$ & 0.82 & 0.86 & 0.89 & 0.86 & -0.01 & -0.08 & -0.08 & 0.92 \\
\hline
\end{tabular}

\begin{tabular}{|l|l|l|l|l|ll|l|l|}
\hline Ws & 1.49 & 1.18 & 1.92 & 1.44 & 0.36 & -0.30 & -0.25 & 0.78 \\
\hline
\end{tabular}

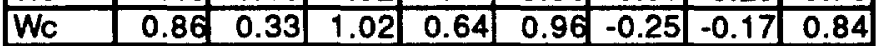

Materials Used in LDH, Fish, and Door - Experimental

\begin{tabular}{|l|l|l|l|l|l|l|l|l|}
\hline $\mathrm{Ni}$ & 1.85 & 1.52 & 2.37 & 1.82 & 0.33 & -0.29 & -0.25 & 0.78 \\
\hline
\end{tabular}

\begin{tabular}{|l|l|l|l|l|l|l|l|l|}
\hline $\mathrm{Nh}$ & 0.72 & 1.21 & 1.03 & 1.04 & -0.32 & -0.30 & -0.35 & 0.70 \\
\hline
\end{tabular}

\begin{tabular}{|l|l|l|l|l|l|l|l|l|}
\hline $\mathrm{Na}$ & 0.64 & 0.65 & 0.61 & 0.64 & -0.04 & 0.05 & 0.05 & 1.05 \\
\hline
\end{tabular}

\begin{tabular}{|l|l|l|l|l|lll|l|}
\hline $\mathrm{Ra}$ & 0.61 & 0.52 & 0.56 & 0.55 & 0.12 & 0.09 & 0.09 & 1.09 \\
\hline
\end{tabular}

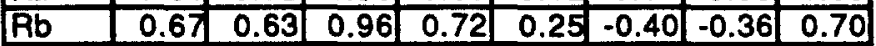

\begin{tabular}{|l|l|l|l|l|l|l|l|l|}
\hline $\mathrm{Kb}$ & 0.62 & 0.71 & 0.92 & 0.74 & 0.07 & -0.40 & -0.39 & 0.67 \\
\hline
\end{tabular}

(8)

\begin{tabular}{|l|l|l|l|l|l|l|l|l|}
\hline $\mathrm{Da}$ & 0.58 & 0.68 & 0.53 & 0.62 & -0.20 & 0.08 & 0.09 & 1.09 \\
\hline
\end{tabular}

The values of $n$ and $m$ refer to strain and strain-rate dependence of flow stress, respectively, in the equation:

$$
\sigma_{a}=K \varepsilon_{a}^{n} \dot{\varepsilon}_{a}^{m}
$$

used to describe the uniaxial stress-strain behavior in the adirection. Other dependencies include that of the friction coefficient, $\mu$, the binder force, $F$, the blank size, $B$, the die lip radius, $d$, and the punch nose radius, $p$.

All the slopes in eqn. (8) are then multiplied by 100 to express them as percent changes.

\section{EXAMPLES: LDR TEST}

In previous works $[1,18]$, different yield criteria in DYNA3D were compared with the LDR observed experimentally, as shown in Fig. 1. The effect of average $\bar{R}$ is shown experimentally and numerically, but also the effect of adding $\Delta R$ instead of assuming $\mathrm{R}=\mathrm{Q}=\mathrm{P}=\bar{R}$. Experimentally, the effect of $\Delta R$ is negligible, and it is also small for the higher-order yield criteria. The dependencies in Fig. 1 are quantified in Table 6 and Figure 6 below.

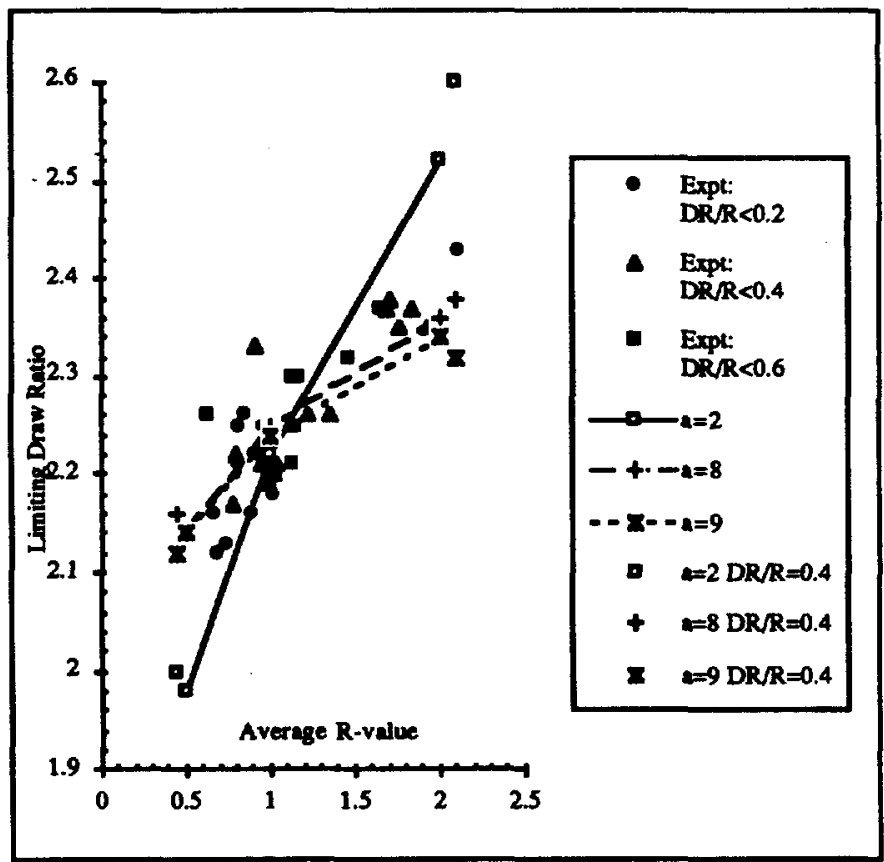

Fig. 1. Effect of $\bar{R}$ and $\Delta R / \bar{R}$ on the LDR as shown experimentally and by the three yield criteria ( $\mathrm{H} 48$ labeled $a=2, H 79$ labeled $a=8$, and $B 89$ labeled $a=9$; exponent is still $a=8$ ). 
EXAMPLES: EARING IN CUPPING

Another draw-intensive comparison again involves the cupping geometry, this time with an emphasis on percent ear formation due to planar anisotropy. In this case, we can define the quantities E45 and E90 as in [18] and previous works, to represent the two types of earing in four-eared cups:

$$
\begin{aligned}
& E 45=\Delta h / h \\
& \Delta h / h=\frac{2 *(h 00-2 * h 45+h 90)}{(h 00+2 * h 45+h 90)} \\
& \Delta R=\left(R-2 * Q_{\omega_{b}}+P\right) / 2 \\
& \bar{R}=\left(R+2 * Q_{\omega}+P\right) / 4 \\
& E 90=\Delta h(0-90) / h \\
& \Delta h(0-90) / h=\frac{4(h 00-h 90)}{(h 00+2 * h 45+h 90)} \\
& \Delta P=R-P \\
& \bar{P}=(R+P) / 2
\end{aligned}
$$

In previous works [1], different yield criteria in DYNA3D were compared with earing observed experimentally, using data obtained by Wilson and Butler [7] with that obtained using simulations with either $a=2$ in eqn. (1) (1948 Hill), $a=8$ in eqn. (5) (1979 Hosford), or $a=8$ in eqn. (6) (1989 Barlat). The dependencies are shown graphically in Fig. 2.

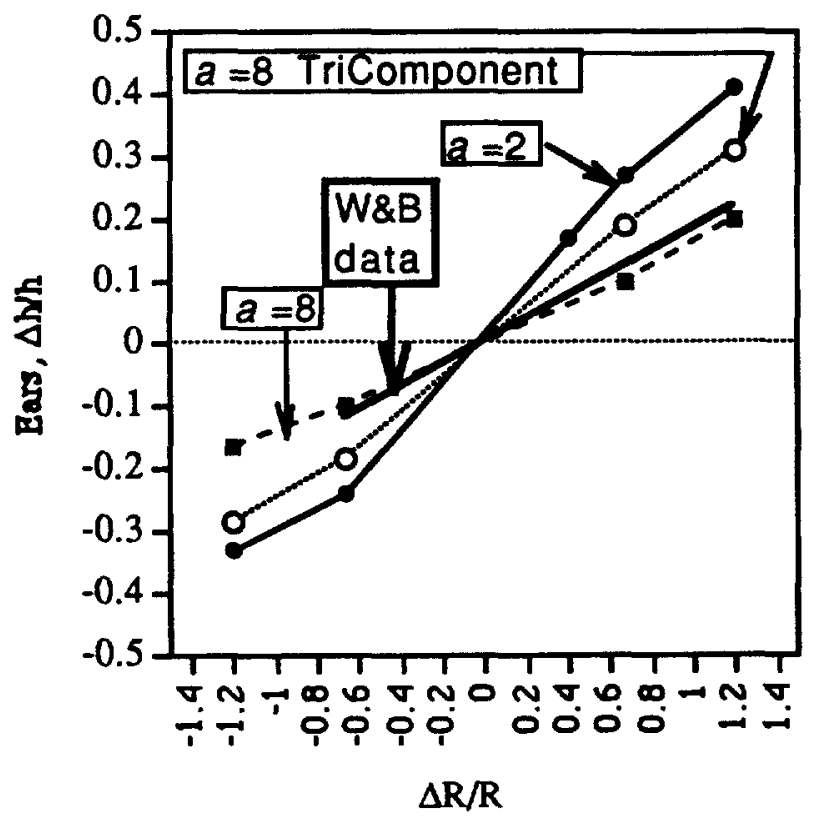

Fig. 2. Plot of earing ( $\Delta h / h$ vs. $\Delta R / R)$ including Wilson and Butler data compared to DYNA results with $a=2$ (48 Hill), $a=8$ (79 Hosford) and $a=8$ (89 Barlat) .
Once again, the slopes of the lines in Fig. 2 will be used to calculate sensitivities expressed in the overall comparison shown below in Table 6 and Fig. 6 .

\section{EXAMPLES: STRETCH-DRAWING CONICAL CUPS}

In previous works [4-6], comprehensive studies were made of the formation of conical cups, where a combination of stretch and draw conditions are necessary to inhibit wrinkling in the unsupported cup wall. These data were revisited for the current work, and the experimental trends were used to calculate $F, B^{\prime}, d^{\prime}$, and $p$ as in eqn. (8). The results are shown in Table 2, with the average values to be used later in the Table 6 overall comparison. Note the very high sensitivity to blank size (B), likely due to the fact that in these experiments the goal is to balance the ability to draw the blank through, yet use the blank and binder to restrain wrinkling in the cup wall.

TABLE 2. Experimentally observed effect of tooling and process and conical cup $\mathrm{H}^{*}$ (Logan, 1984)

\begin{tabular}{|l|r|r|r|r|r|r|}
\hline Slope & CRst & $325 t$ & $215 t$ & 252 & 252 & Slope \\
& F16T & F21T & F23T & F28T & F29T & Avg. \\
\hline$F^{\prime}$ & -60 & -28 & -14 & -33 & & -34 \\
\hline$B^{\prime}$ & -300 & & & & -100 & -200 \\
\hline$d^{\prime}$ & 21 & 22 & 13 & & & 19 \\
\hline$P^{\prime}$ & 67 & 15 & 15 & 17 & & 29 \\
\hline
\end{tabular}

\section{EXAMPLES: LDH GEOMETRY}

The recent LDH benchmark (SB-1) described in NUMISHEET 96 [2] can provide much data and insight into sensitivity to material parameters and friction, since numerous entrants studied these sensitivities numerically on forming the LDH geometry as shown in Figs. 3-4 with a variety of codes. Results on the dependence of $\mathrm{H}^{+}$on anisotropy obtained by one of the authors are reproduced below in Table 3.

TABLE 3. Effect of $\boldsymbol{R}$ and a on $\mathrm{H}^{*}$ in LDH Test

\begin{tabular}{|l|r|r|r|r|}
\hline Materal & $\bar{R}$ & $\Delta R / \bar{R}$ & $\begin{array}{r}L D H \\
a=2\end{array}$ & $\begin{array}{r}\text { LDH } \\
a=8\end{array}$ \\
\hline Ni-IF & 7.00 & & 39.2 & 38.0 \\
\hline & 1.64 & & 44.0 & 37.6 \\
\hline & 1.82 & & 45.6 & 37.6 \\
\hline & 1.82 & 0.00 & 44.0 & 37.4 \\
\hline & 2.00 & & 46.8 & 37.6 \\
\hline Nh-HS & 0.94 & & 32.0 & \\
\hline & 1.00 & 0.00 & 33.2 & \\
\hline & 1.04 & & 32.8 & \\
\hline & 1.14 & & 33.6 & \\
\hline Na-AL & 1.20 & & 37.6 & \\
\hline & 0.57 & & 29.6 & \\
\hline & 0.64 & & 29.6 & \\
\hline & 0.71 & & 29.8 & \\
\hline & 1.00 & 0.00 & 30.4 & \\
\hline & 1.00 & & 30.4 & \\
\hline
\end{tabular}

In addition, the numerical analyses were repeated using the higher order $\mathrm{H} 79$ yield criterion " $\mathrm{a}=8$ " 
to supplement the " $a=2 " H 48$ results. For this predominantly stretch test, the dependence of $\mathrm{H}^{+}$on $R$ values nearly disappears when " $a=8$ " is used, as shown in the right-most column of Table 3.

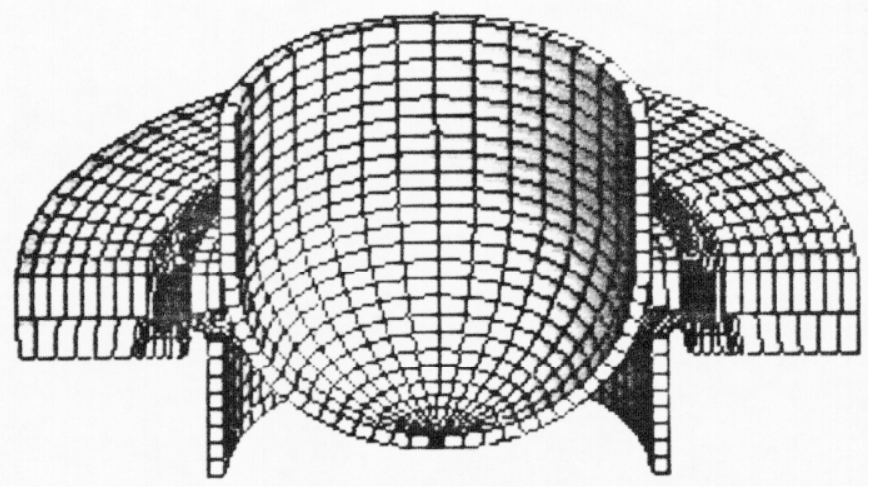

Fig. 3. LDH tooling used to clamp and form dome punch, die, and binder used to form part below.

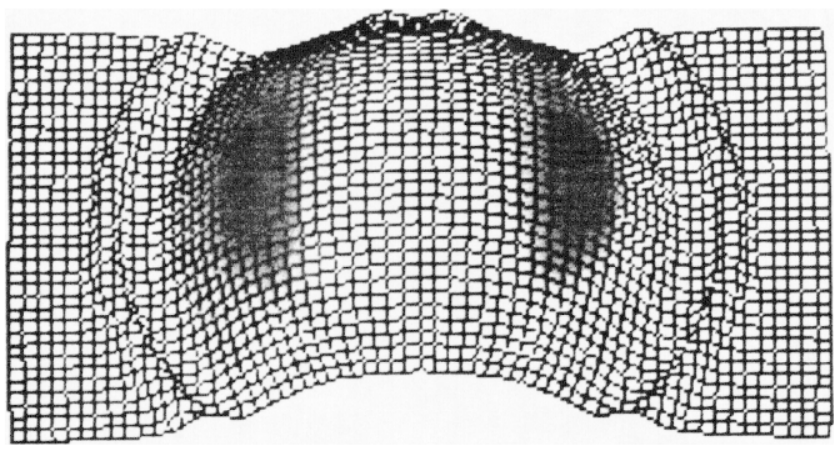

Fig. 4. LDH geometry formed with W-DYNA3D and the H79 yield criterion with " $a=8$ ". Failure fraction " $\mathrm{a}$ " is plotted showing proximity to the Forming Limit Diagram (FLD). FLD is reached when $f>1$ (dark areas).

Using data such as that shown in Table 3, sensitivity parameters as in eqn. (8) were calculated for all the NUMISHEET 96 entrants that reported sensitivity data. These are shown below in Table $4 a$ for Material if (Interstitial-Free Steel), in Table $4 b$ for Material HS (High-Strength Steel), and Table $4 \mathrm{C}$ for Material $\mathrm{AL}$ (Aluminum 6111-T4). Many of the slopes as defined in eqn. (8) are calculated for each entry (as numbered in the proceedings), with the average then taken for each material. These averages are again transferred to Table 6 for the overall comparison.
TABLE 4a. Summary of LDH sensitivities - from NUMISHEET 96 SB-1, Material IF

\begin{tabular}{|l|r|r|r|r|r|r|r|r|}
\hline Entry: & 6 & 15 & 18 & 18 & 20 & 24 & 25 & avg \\
\hline Slope & & & & & & & & \\
\hline$R^{\prime} a=2$ & & 22 & 7 & $+1-0$ & & 31 & 11 & 14 \\
\hline$R^{\prime} a<2$ & & & & & 56 & & & 56 \\
\hline$R^{\prime} a=8$ & & & & & & 0 & & 0 \\
\hline$\Delta R^{\prime} a=2$ & & & & & & 4 & & 4 \\
\hline$n^{\prime}$ & & 22 & -9 & 29 & 0 & 38 & 13 & 16 \\
\hline$m^{\prime}$ & & & & & 11 & 7 & & 9 \\
\hline$\mu^{\prime}$ & -33 & -20 & -7 & 0 & -11 & -17 & -7 & -14 \\
\hline$F^{\prime}$ & & & -111 & & & & & \\
\hline
\end{tabular}

TABLE 4b. Summary of LDH sensitivities - from NUMISHEET 96 SB-1, Material HS

\begin{tabular}{|l|r|r|r|r|r|r|r|}
\hline Entry: & 18 & 19 & 20 & 24 & 25 & 28 & avg \\
\hline Slope & & & & & & & \\
\hline$R^{\prime} a=2$ & 56 & 13 & & 25 & 69 & & 41 \\
\hline$R^{\prime} a<2$ & & & 62 & & & $+1-0$ & 31 \\
\hline$R^{\prime} a=8$ & & & & & & & \\
\hline$\Delta R^{\prime} a=2$ & & & & & & & \\
\hline$n^{\prime}$ & 28 & 28 & 31 & 50 & 66 & 88 & 49 \\
\hline$m^{\prime}$ & & & 0 & 9 & & 31 & 13 \\
\hline$\mu^{\prime}$ & -53 & 0 & -16 & -18 & -9 & 0 & -16 \\
\hline$F^{\prime}$ & -218 & & & & -66 & & -142 \\
\hline
\end{tabular}

TABLE 4C. Summary of LDH sensitivities - from NUMISHEET 96 SB-1, Material AL

\begin{tabular}{|l|r|r|r|r|r|r|r|}
\hline Entry: & $\mathbf{1 8}$ & $\mathbf{1 9}$ & $\mathbf{2 0}$ & $\mathbf{2 2}$ & $\mathbf{2 4}$ & $\mathbf{2 5}$ & avg \\
\hline Slope & & & & & & & \\
\hline $\mathrm{R}^{\prime} \mathrm{a}=2$ & & 14 & & & 3 & & 9 \\
\hline $\mathrm{R}^{\prime} \mathrm{a}<2$ & & & & & & \\
\hline $\mathrm{R}^{\prime} \mathrm{a}=8$ & 10 & & & & & 0 & 5 \\
\hline$\Delta \mathrm{R}^{\prime} \mathrm{a}=2$ & & & & & 0 & & $\mathbf{0}$ \\
\hline$n^{\prime}$ & -14 & 31 & 17 & & 34 & $+1-0$ & 14 \\
\hline$m^{\prime}$ & & & 0 & & 3 & & 2 \\
\hline$\mu^{\prime}$ & -10 & 0 & 0 & -20 & -14 & $+1-0$ & -7 \\
\hline$F^{\prime}$ & -172 & & & & & $+1-0$ & -86 \\
\hline
\end{tabular}

EXAMPLES: "FISH" COVER, DOOR FRAME, ETC.

Having assembled several simple test geometries for comparison of sensitivities to anisotropy and other prameters, we wished to explore these dependencies in progressively more complex geometric stampings as well. A related study was perfomed recently [1] on rectangular box and cup geometries that looked at percentage improvements in the Adjusted Draw Depth (ADD), or roughly speaking, $\mathrm{H}^{*}$ as in this work but compensated to produce a stamping using a minimum of material subject to a minimum final thickness being achieved throughout the part. This information was already in a form nearly equivalent to those in eqn. $(8)$, and the summary of this work (Table 6 ) reflects the findings in [1].

As additional examples, one part that was reconsidered involves a hydroformed cover first studied some years ago using 6061-0 aluminum by Maker [10]. 
This part is made in a hydroforming operation described in [10], and has been analyzed usingvarious versions of DYNA3D, NIKE3D, LS-DYNA3D, and LS-NIKE3D. On forming the part as shown in Fig. 5, the "fish-like" part has a tendency to tear in the wall near the tail of the fish. The four close-ups surrounding the full fish show qualitatively the effect of blank positioning on the strain distribution as the FLD is approached. These represent four separate runs using the "Ra" material, which has a high $R_{90}$ relative to $R_{0}$ and $R_{45}$. When the rolling direction is aligned with the fish axis, the failure fraction "f" shows the distribution in the top insets, with slight differences depending on whether the " $a=2$ " or " $a=8$ " yield criterion is used. If the blank is turned 90 degrees, the distributions of " $f^{n}$ in the lower insets result. The failure heights $\mathrm{H}^{*}$ are also different; each of the inset pictures was taken at its respective $\mathrm{H}^{*}$.

In all, numerous analyses were done using different lots and placement of 6111-T4 aluminum as a blank material, chosen for this part of the numerical study due to the relative abundance of data available for it. The baseline properties were used as given in the NUMISHEET 96 benchmark, and different sets of actual $R$-values were then used as permutations. The resulting $\mathrm{H}^{*}$ depths are shown in the top half of Table 5, for both " $a=2$ " and " $a=8$ ". Worthy of note are the differences between the two, with the " $a=8$ " results having higher $\mathrm{H}^{*}$ since the yield surface, though it is sharper, is pulled out more toward the Von Mises condition. In fact, even for isotropy the " $a=8$ " has a higher $\mathrm{H}^{\star}$, perhaps indicating that easier flow in shear is allowing the complex shaped blank to draw in more easily. Once again, the 90 degree rotated position for the $\mathrm{Rb}$ and $\mathrm{Kb}$ materials (see Table 1) gives much higher $\mathrm{H}^{*}$, as well as a different qualitative strain distribution as shown in Fig. 5.

In addition to $\mathrm{H}^{*}$, various slopes were calculated per eqn. (8), and are given in the appropriate positions in Table 5 . In each case, a given slope was obtained by comparing the conditions and $\mathrm{H}^{*}$ from the two analyses in the superscript of the slope; that is, a superscript (45) means that analyses (4) and (5) were used to get the slope. Of particular note is the high slope (R/P)', as already discussed, as well as the high slope for $R^{\prime}$.

Also supplied in the lower half of Table 5 are the $\mathrm{H}^{*}$ for a closed-die door frame stamping as described in detail elsewhere [11]. This stamping was analyzed with DYNA3D as the first step in a multi-stage forming operation with intermediate anneals, using a mesh of nearly 40,000 elements in the sheet. The analysis had been performed in [11] using isotropic properties and an FLD as reported by Dorward [8], and was repeated here with the R-values as reported in [8] as well; runs with and without planar anisotropy showed little discernable difference in this case, although the slope $R^{\prime}$ was again quite high.

\section{SUMMARY: OVERALL SENSITIVITIES}

From the various experimental and numerical studies discussed above, the sensitivity slopes as defined in eqn. (8) were compiled into the form shown in Table 6 to allow comparison of the various slopes with each other, and for a variety of sheet forming processes and materials. The most significant factor worth noting in Table 6 is the variation in magnitude of any given slope depending on the piece being formed (and material as in the LDH tests). In fact, the variations are similar in magnitude to the larger set of LDH data from the different entries to NUMISHEET 96 as shown in Table $4 a-c$. This suggests that not only are the numerically observed sensitivity slopes dependent on the forming scenario, they are also somewhat dependent on the code implementation and assumptions in setting up a given simulation. However, on the whole, the directions of the dependencies are the same in Table 6 as well as Table 4, with only a few exceptions to the trends. Even these have reasonable explanations for the most part. For example, in Table 6, the slope $\Delta R$ and (R/P)' is negative for the Adjusted Draw Depth (ADD) for the cup forming operation, and for the E45 and E90 earing in cylindrical cups, whereas $\Delta R^{\prime}$ is generally positive regarding $\mathrm{H}^{*}$. This is because it is often possible (as in the fish cover) to utilize planar anisotropy to our advantage given a non-axisymmetric geometry and an intelligent choice of blank position. However, if we consider the axisymmetric cup, the presence of earing is only a detriment in most measures of $\mathrm{H}^{*}$. For this reason, we include in Table 5 (in parentheses) another slope, which is based on the magnitude of all the $\Delta R^{\prime}$ and $(R / P)^{\prime}$, rather than allowing a positive and negative slope to cancel. Another apparent anomaly (in Table 4a and $4 c$ ) is the negative value of $n^{\prime}$ observed by entry \#18. However, in that case the n-value was changed without changing the value of $K$ in eqn. (9), so that raising $n$ has the numerical side effect of lowering the yield stress, leading to a potentially lower $\mathrm{H}^{*}$ depending on friction interactions.

Overall, if the Tables 4-6 are examined carefully and factors such as these are considered, there is indeed a great deal of consistency among the trends, and certainly the averages of all the slopes give a good overall indication of the relative importance of anisotropy compared to other material and forming parameters. This comparison is shown more graphically in Fig. 6 , which is simply a bar chart of all the magnitudes of dependencies in the far right column of Table 6 . The only special cases in Fig. 6 are the values of $F^{\prime}$ and $B^{\prime}$, which were divided by 10 in order to fit reasonably on the same chart. If we note then that these two parameters have nearly an order of magnitude more influence than the others, a legible comparison of the rest of the slopes can be made from Fig. 6. Overall, for materials that are well characterized by the " $a=2$ " $(\mathrm{H} 48)$ criterion, anisotropy is among the highest influences on the slopes of eqn. (8) and thus on $\mathrm{H}^{*}$ in a given forming operation. For materials following an " $\mathrm{a}=8$ " criterion, the anisotropy dependencies (grouped together in Fig. 6) are less strong, but still of much the same order as the other slopes on the chart.

\section{CONCLUSIONS}

We have examined the dependence of punch depth to failure (encroachment on FLD) in a variety of sheet forming situations, to a range of material and process parameters. For the cases considered (and the metrics used via eqn. (8)), the strongest normalized dependencies appear as those on binder force $(F)$, and blank size $(B)$. Beyond those factors, the magnitude of influence of anisotropy is certainly comparable to the other material and process parameters (strain and rate effect, friction, tooling geometry) whose knowledge is considered essential to a quality analysis. 


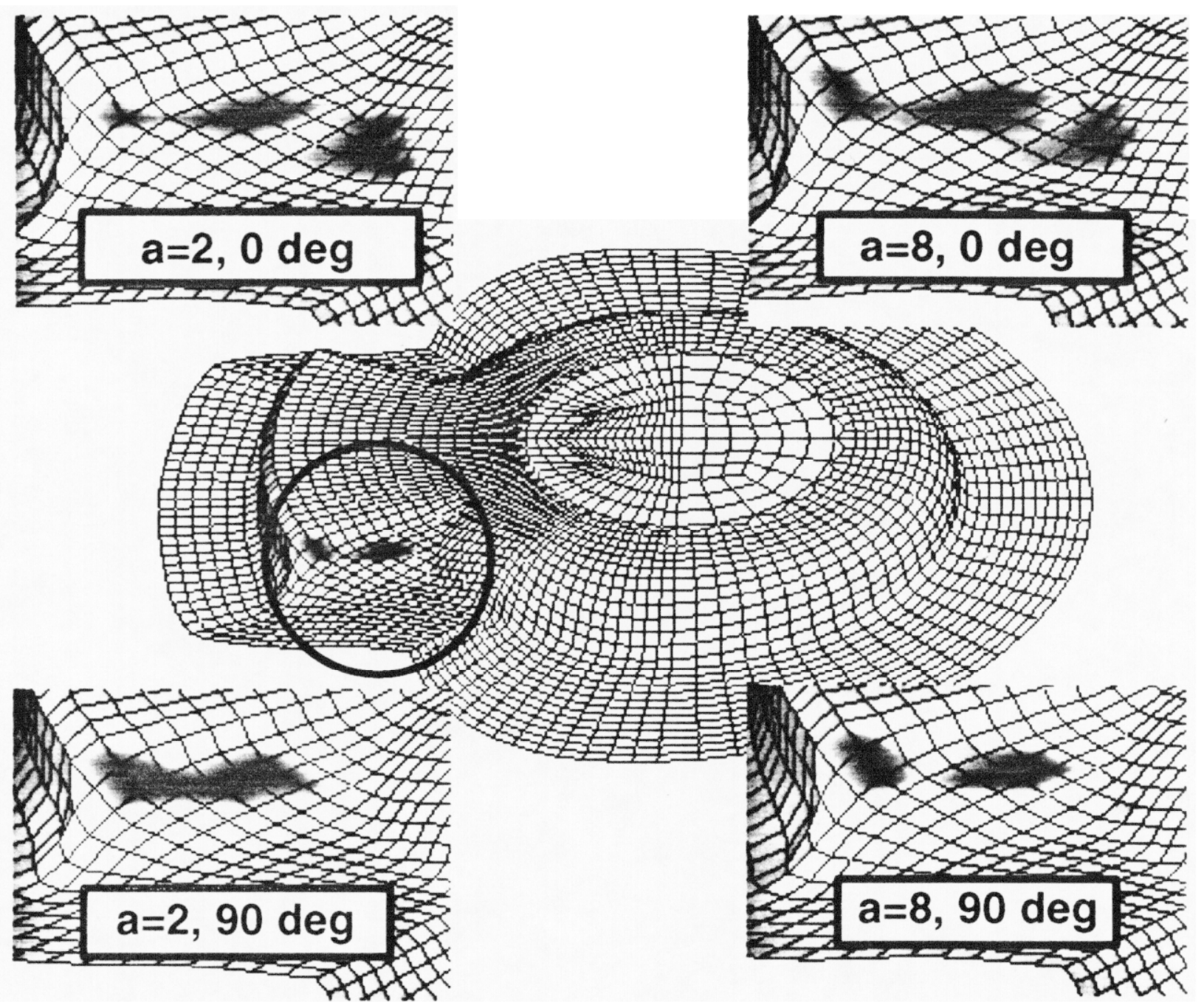

Figure 5. "Fish cover" hydroformed part, analyzed with 6111-T4 aluminum (Rb) using different blank placement and choice of yield criterion (" $a=2$ " is 1948 Hill, " $a=8$ " is 1979 Hosford).

TABLE 5. Predicted effect of anisotropy on $\mathrm{H}^{*}$ for complex stampings

\begin{tabular}{|c|c|c|c|c|c|c|c|c|c|}
\hline Part & Material & $\begin{array}{c}\mathrm{H}^{*} \\
\mathrm{a}=2\end{array}$ & $\underset{a=8}{H}$ & $\begin{array}{r}\text { Slope } \\
R^{\prime} \\
a=2 \\
\end{array}$ & $\begin{array}{r}\text { Stope } \\
\Delta R \\
a=2 \\
\end{array}$ & $\begin{array}{r}\text { Slope } \\
(R / P)^{\prime} \\
a=2\end{array}$ & $\begin{array}{r}\text { Slope } \\
R^{\prime} \\
a=8 \\
\end{array}$ & $\begin{array}{r}\text { slope } \\
\Delta R^{\prime} \\
\mathrm{a}=8\end{array}$ & $\begin{array}{r}\text { Slope } \\
(R / P)^{\prime} \\
a=8\end{array}$ \\
\hline \multicolumn{10}{|l|}{$\begin{array}{l}\text { Fish } \\
\text { Cover- } \\
6111-T 4\end{array}$} \\
\hline & 1.VonMises & 28.0 & 29.2 & & & & & & \\
\hline & 2.Na & 24.1 & 26.7 & & & & & & \\
\hline & 3.Ra & 24.1 & 26.7 & & & & & & \\
\hline & 4.Rb & 28.0 & 28.4 & & $10.2^{(45)}$ & & & $6.4^{(45)}$ & \\
\hline & 5.Rb-avg & 25.4 & 26.7 & $33.0^{(15)}$ & & & $33.0^{(15)}$ & & \\
\hline & 6.Rb-rot.90 & 24.1 & 26.7 & & $5.1^{(56)}$ & $21.0^{(46)}$ & & $0.0^{(56)}$ & $9.0^{(46)}$ \\
\hline & $7 . \mathrm{Kb}$ & 28.0 & 29.2 & & & & & & \\
\hline & 8. Kb-rot.90 & 22.9 & 26.7 & & & $24.6^{(78)}$ & & & $11.5^{(78)}$ \\
\hline \multicolumn{10}{|l|}{$\begin{array}{l}\text { Door } \\
\text { Frame- } \\
2024-0 \\
\end{array}$} \\
\hline & 7.Vonmises & 18.3 & & & & & & & \\
\hline & 2.Da & 76.7 & & & & & & & \\
\hline & 3.Da-avg & 16.7 & & $25.0^{(3)}$ & $0.0^{(23)}$ & & & & \\
\hline
\end{tabular}


TABLE 6. Summary of Sensitivity of failure height $\left(H^{*}\right)$ to anisotropy and other parameter slopes

\begin{tabular}{|c|c|c|c|c|c|c|c|c|c|c|c|c|c|}
\hline Slope & LDR & $\begin{array}{c}\text { LDH, } \\
\text { N96-IF }\end{array}$ & $\begin{array}{r}\text { LDH, } \\
\text { N96- } \\
\text { HS }\end{array}$ & $\begin{array}{r}\mathrm{LDH} \\
\mathrm{N} 96- \\
\mathrm{AL}\end{array}$ & $\begin{array}{l}\text { Conic } \\
\text { Cups }\end{array}$ & $\begin{array}{r}\text { Cyl. } \\
\text { Cups }\end{array}$ & $\begin{array}{l}\text { Box, } \\
\text { ADD }\end{array}$ & $\begin{array}{l}\text { Box, } \\
\text { PTS }\end{array}$ & $\begin{array}{l}\text { Cup. } \\
\text { ADD }\end{array}$ & $\begin{array}{l}\text { Cup, } \\
\text { PTS }\end{array}$ & $\begin{array}{r}\text { Fish, } \\
\mathbf{H}^{*}\end{array}$ & $\begin{array}{r}\text { Door, } \\
\mathrm{H}^{*}\end{array}$ & $\begin{array}{r}\text { AVG. } \\
\text { O/A }\end{array}$ \\
\hline$R^{\prime}, a=2$ & 39 & 14 & 41 & 9 & & & 24 & (16) & 38 & (36) & 33 & 25 & 27 \\
\hline$R, a=8$ & 19 & 0 & & 5 & & & 8 & (0) & 9 & (B) & 33 & & 12 \\
\hline$R^{\prime}, a<2$ & & 56 & 31 & 0 & & & & & & & & & 29 \\
\hline$\Delta \mathrm{A}^{\prime}, \mathrm{a}=2$ & 8 & 4 & & 0 & & -12 & 2 & (20) & -21 & & 8 & $\overline{0}$ & $(7)-1$ \\
\hline$\triangle \mathrm{A}^{\prime}, \mathrm{a}=\mathrm{B}$ & 2 & & & & & -6 & 2 & (0) & -5 & & 3 & & (4) -1 \\
\hline (R/P), $\mathrm{a}=2$ & & & & & & -12 & & & & & 23 & & $(17) 5$ \\
\hline$(R / P)^{\prime}, a=8$ & & & & & & -6 & & & & & 10 & & $(8) 2$ \\
\hline$n^{\prime}$ & 8 & 16 & 49 & 14 & & & & & & & & & 21 \\
\hline$m^{\prime}$ & & 9 & 13 & 2 & & & & & & & & & 8 \\
\hline$\mu^{\prime}$ & -12 & -14 & -16 & -7 & & & & & & & & & -12 \\
\hline$F$ & & -79 & -142 & -86 & -34 & & & & & & & & -85 \\
\hline $\mathrm{B}^{\prime}$ & & & & & -200 & & & & & & & & -200 \\
\hline$d^{\prime \prime}$ & & & & & 19 & & & & & & & & 19 \\
\hline $\mathrm{p}^{\prime}$ & & & & & 29 & & & & & & & & 29 \\
\hline
\end{tabular}

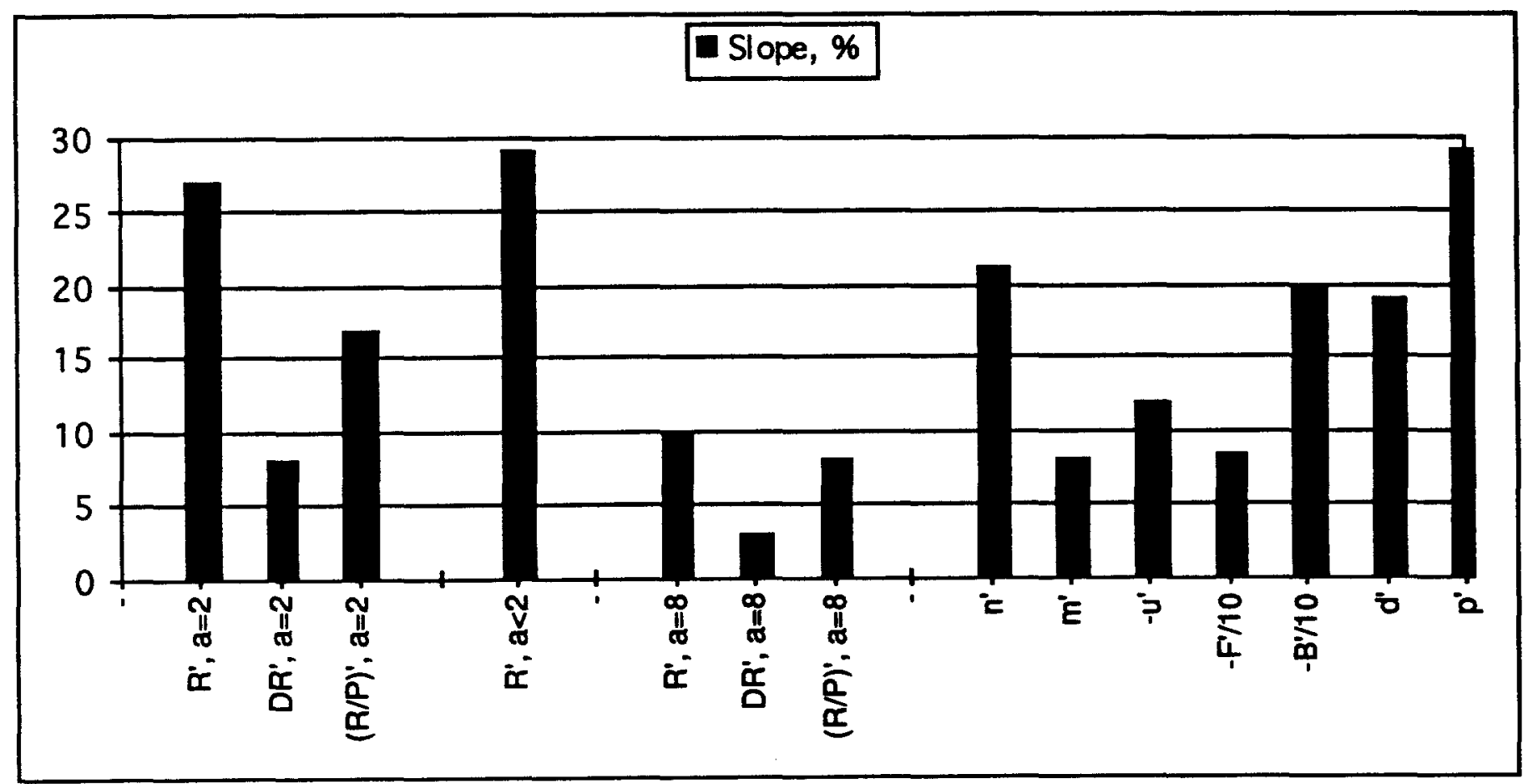

Figure 6. Graphical depiction of normalized dependencies of $\mathrm{H}^{*}$ on material and process parameters. All are plotted as magnitude even if a negative dependence is actually observed. The values of $F$ and $B$ ' are divided by 10 to appear legible on the same chart.

There are several notable caveats to the methodology presented herein. Although it indeed simplifies the various effects, it is virtually impossible to let any single material parameter, including the set of $R$ values, change without causing other changes. Thus, while it was assumed in this work that the set of R-

values had no effect on flow stress or the shape and position of the FLD, some interdependencies are likely. Similarly, changes in the $n$-value virtually never occur without some change in the effective $K$-value of eqn. (9); indeed even in Table 4 the entrants had to either consider $K$ to be constant (as did \#18), or to consider yield stress (at some finite plastic strain) to be constant, so that $K$ effectively varies with $n$. 
Furthermore, the full effect of rate sensitivity ( $\mathrm{m}^{\prime}$ ) in postponing localized necking and failure will be missed without a local damage theory. These latter topics need to be more carefully sorted for future works. Meanwhile, the dependencies shown in Fig. 6 should still give most readers a good general impression of the relative importance of these parameters.

\section{ACKNOWLEDGMENTS}

- The authors wish to thank the organizers and participants of NUMISHEET 96 for timely inspiration to compile this work. A.J. Beaudoin of Reynolds Metals,

- S.M. Miyasato of Kaiser Aluminum, and A.J. Sunwoo of LLNL helped obtain timely data on 6111-T4. Portions of this work were performed under the auspices of the U.S. Department of Energy by the Lawrence Livermore National Laboratory under contract W-7405-Eng-48.

\section{REFERENCES}

1. Logan, R.W., "Use of Non-Quadratic Yield Surfaces in Design of Optimal Deep-Draw Blank Geometry", SAE paper 960597, in Sheet Metal Stamping for Automotive Applications, SP-1134, SAE, Warrendale, PA (1996), p. 61.

2. Lee, J.K., Kinzel, G.L., and Wagoner, R.H., "NUMISHEET' 96", Proc. 3rd Int"l Conf: Numerical Simulation of 3D Sheet Metal Forming Processes, The Ohio State University (1996).

3. Logan, R.W., Meuleman, D.J., and Hosford, W.F., "The Effects of Anisotropy on the Limiting Drawing Ratio", in Formability and Metallurgical Structure, eds. A.K. Sachdev and J.D. Embury, TMS-AIME, (1987) p.159.

4. Havranek, J. "Wrinkling Limit of Tapered Pressings", J. Aust. Inst. Metals 20 (1975) p. 114

5. Havranek, J. in Sheet Metal Forming and Energy Conservation, Proc. 7th IDDRG (1977) p. 245

6. Logan, R.W., "Sheet Metal Formability: Simulation and Experiment", PhD Thesis, University of Michigan (1985).

7. Wilson, D.V. and Butler, R.D., "The Role of CupDrawing Tests in Measuring Drawability", J. Inst. Metals 90, (1962) p. 473.

8. Donward, R.C., "Forming Characteristics of Coarse and Fine-Grained AA 2024 Aluminum Alloy Sheet", J. Mater. Engineering and Performance 3 (1994), p. 115.

9. Kobayashi, S., Oh, S.I., and Altan, T., Metal Forming and the Finite-Element Method, Oxford Univ. Press, New York. (1979).

10. Maker, B.N., "Finite Element Modeling of a Hydroformed Sheet Metal Cover", UCID-21614, Univ. California, LLNL (1988).

11. Logan, R.W., Thomas, D.B., and Young, G.K., "Implementation of a Pressure and Rate Dependent Forming Limit Diagram Model into NIKE and DYNA", in MED-Vol. 1, Concurrent Product and Process Engineering, ed. A.R. Thangaraj, R. Gadh, and S. Billatos, ASME Book H01017 (1995).
12. Hill, R., The Mathematical Theory of Plasticity, Clarendon Press, Oxford (1948).

13. Hill, R., Theoretical Plasticity of Textured Aggregates", Math. Proc. Cambridge Phil. Soc. 75 (1979) p. 179.

14. Hosford, W.F., "On Yield Loci of Anisotropic Cubic Metals", Proc. 7th' N. Amer. Metal Working Research Conf., SME, Dearborn (1979) p. 191.

15. Barlat, F. and Lian, J., "Plastic Behavior and Stretchability of Sheet Metals, Part I: A Yield Function for Orthotropic Sheets Under Plane Stress Conditions", Int. J. Plasticity 5, (1989) pp. 51-66.

16. Hallquist, J.O., LS-DYNA3D Theoretical Manual, Livermore Software Technology Corp., Livermore, CA (1993).

17. Maker, B.N. and Hallquist, J.O., LS-NIKE3D Theoretical Manual, Livermore Software Technology Corp., Livermore, CA (1993).

18. Logan, R.W., "Implications of a 'Cross-Rolled' Yield Surface Approximation On Deep Drawing", in NUMISHEET 96, Proc. 3rd Int'l Conf: Numerical Simulation of 3D Sheet Metal Forming Processes, eds. Lee, J.K., Kinzel, G.L., and Wagoner, R.H., The Ohio State University (1996). 


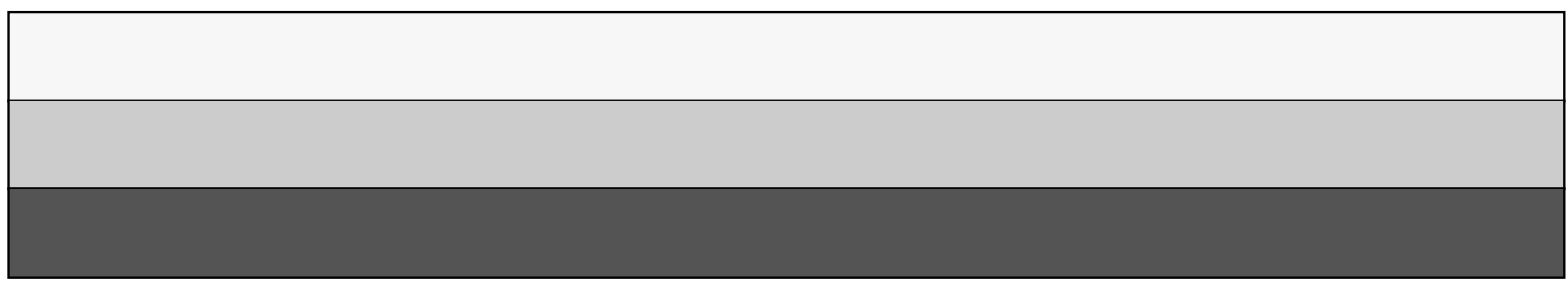

